\title{
A SIMPLE NONPARAMETRIC TEST FOR TESTING TREATMENT VERSUS CONTROL
}

\section{K. S. MADHAVA RAO and M. RAGHUNATH}

Department of Statistics

University of Botswana

Private Bag 00705

Gaborone

Botswana

e-mail: raom@mopipi.ub.bw

Department of PG Studies in Statistics

SDM College

Ujire

India

\begin{abstract}
In testing whether a treatment has an effect or not, the experimenter is often obliged to use the same subjects for control and treated groups. In such a case, it is generally unrealistic to assume independence and one is led to tests of bivariate symmetry. In the nonparametric setup, Hollander [3] proposed a conditionally distribution-free test for bivariate symmetry based on the sample distribution function. The hypothesis of interest considered by him was that the bivariate random variables $(X, Y)$ are exchangeable or equivalently, the hypothesis of treatment versus control. The equivalence between the hypothesis of exchangeability and the hypothesis of conditional symmetry about an axis is central to the motivation behind the proposed test. The test is based on a
\end{abstract} 2010 Mathematics Subject Classification: 62G10, 62G20, 62H15.

Keywords and phrases: bivariate symmetry, conditional symmetry, empirical power, non parametric test.

Received September 13, 2016

(C) 2016 Scientific Advances Publishers 
measure of deviance between observed counts of bivariate samples in suitably defined pairs of sets. It is shown that the test is distribution-free and the exact null distribution can be easily computed. For sample size from $n=5$ up to $n=30$, the table of exact distribution is provided. For sufficiently large $n$, a chi-square approximation is provided. The empirical power of the proposed test is evaluated by simulating samples from suitable classes of symmetric and asymmetric bivariate distributions. It is shown that the test performs reasonably well as compared to its parametric (Bell and Haller [1]) and nonparametric competitors (Hollander [3] and Wilcoxon [8]).

\section{Introduction}

Suppose we have $2 n$ observations, two observations on each of $n$ subjects. We shall assume that these $n$ bivariate observations $\left(X_{1}, Y_{1}\right), \ldots,\left(X_{n}, Y_{n}\right)$ are mutually independent and each $\left(X_{i}, Y_{i}\right)$, $i=1, \ldots, n$ comes from the same bivariate population with the joint distribution function $F(x, y)$. The null hypothesis of interest here is that the $X$ and $Y$ are exchangeable or, equivalently, there is no treatment effect. Thus, the hypotheses related to no treatment effect can be written as

$$
\mathrm{H}_{0}: F(x, y)=F(y, x) \text { for all }(x, y) \in \mathfrak{R}^{2} \text {, }
$$

against the alternative

$$
\mathrm{H}_{1}: F(x, y) \neq F(y, x) \text { for some }(x, y) \in \mathfrak{R}^{2} .
$$

Another way to state this exchangeability property is that the pairs $(X, Y)$ and $(Y, X)$ have the same joint bivariate distribution. The hypothesis $\mathrm{H}_{0}$ is a natural one when an experimenter is testing for a treatment effect and finds it convenient (or necessary) to have the same subjects receive the treatment and also act as controls. Since $\left(X_{i}, Y_{i}\right)$ then represent two observations on the same subject, it is unrealistic to assume that $X_{i}$ and $Y_{i}$ are independent. The hypothesis of no treatment effect is precisely $\mathrm{H}_{0}$. Terms used by various researchers to describe $\mathrm{H}_{0}$ include exchangeability, interchangeability, and bivariate symmetry. 
In the nonparametric setup, Hollander [3] proposed a test for bivariate symmetry. Given the bivariate data $\left(X_{1}, Y_{1}\right), \ldots,\left(X_{n}, Y_{n}\right)$, Hollander's bivariate symmetry test is based on the statistic $n D_{n}$, where

$$
\begin{gathered}
D_{n}=\iint\left\{F_{n}(x, y)-F_{n}(y, x)\right\}^{2} d F_{n}(x, y) d x d y, \\
F_{n}(x, y)=n^{-1} \sum_{j=1}^{n} \varphi\left(X_{j}, x\right) \varphi\left(Y_{j}, y\right),
\end{gathered}
$$

and, $\varphi(a, b)=1$ if $a \leq b,=0$ otherwise. In order to carry out the test, Hollander gave an exact and an approximate method of computing $n D_{n}$. It is pertinent to mention that the test based on $n D_{n}$ is neither distribution-free, nor asymptotically distribution-free. As pointed by Hollander even the asymptotic distribution under the null hypothesis seems to be intractable. Since $n D_{n}$ lacks the unconditionally distribution-free property, Hollander turned to a conditional test which depends on a suitably defined group $G$ of $2^{n}$ transformations. Even in the case of this conditional test, Hollander acknowledges that, it is possible, though extremely tedious for large $n$, to table the null distribution of $n D_{n}$. A FORTRAN program need to be sourced to obtain the cut off points to carry out the test based on $n D_{n}$. The conditional test leads to the rejection of $\mathrm{H}_{0}$ for large values of $n D_{n}$. Hollander also carried out power comparisons of $D_{n}$ with respect to a normal theory test devised by Bell and Haller [1] and the Wilcoxon [8] signed rank test for bivariate normal and bivariate exponential distributions. Finally, the test based on $n D_{n}$ is computationally laborious and moreover, for its actual implementation, no null distribution seem to be readily available, given bivariate samples of different sizes.

Hilton [2] gave an elegant computational method of the Hollander statistics. Following his notations, Hollander's bivariate symmetry statistic, can be written as $h(s)=T^{\prime} T$, where, $T=d^{\prime} s$, depends on a particular permutation of the data, represented by the $n$-vectors $s$, where 
$s_{i}=I\left\{y_{i} \leq x_{i}\right\}-I\left\{y_{i}>x_{i}\right\}, i=1, \ldots, n$ and on the conditional sample space, represented by the $n \times n$ matrix $d . I\{z\}$ is an indicator function equaling 1 when $z$ is true and 0 otherwise. To define $d$, transform the data to $a_{i}=\min \left(y_{i}, x_{i}\right)$ and $b_{i}=\max \left(y_{i}, x_{i}\right), i=1, \ldots, n$ and then transform $(a, b)$ pairs to $d$, where, $d_{i, j}=I\left\{a_{i} \leq a_{j} ; a_{j}<b_{i} \leq b_{j}\right\}$. Hilton denoted the observed statistic by $h\left(s^{*}\right)=T^{\prime} T$, whereas Hollander standardized and denoted it by $n D_{n}=n^{-2} T^{\prime} T$. The asymptotic distributions of the bivariate symmetry test $D_{n}$ were derived by Hollander [3] and by Koziol [6]. Kepner and Randles [5] reported that "Koziol's critical values greatly improved test's ability to achieve the specified significance level as compared to the large sample critical value approximations originally suggested by Hollander". However, studying $n=15$ and 25 and for the covariance of the paired samples, $\sigma_{12}=0.30$ and 0.80 , they found that in small samples "Hollander's statistic appears to do quite poorly at maintaining significance level when the observations within pairs are highly correlated". Continuing with the work of Koziol [6], Hilton [2] showed that asymptotic distribution of the bivariate symmetry statistic standardized by $1 / n^{2}$ is invalid for all $n$, where $n$ is the number of iid pairs of observations from the bivariate distribution $F$. $\mathrm{He}$ also established that the asymptotic test fails to account for the conditional nature of the statistics and consequently is unpredictably very liberal or very conservative even for $n$ as large as 96. Therefore, Hilton provided an alternative standardization of bivariate symmetry statistic that adjusts it for the covariance of the paired samples $\sigma_{12}$ as well as $n$. He showed that size of the new asymptotic test is very close to the nominal level, even for small $n$. These additional findings lead to the necessity of an alternative to Hollander's test of bivariate symmetry.

In this paper, we propose a simple nonparametric test for testing the hypothesis of bivariate exchangeability based on a count statistic, which is exactly distribution-free under $\mathrm{H}_{0}$ and is easy to implement. The proposed test is based on a measure of deviance between the observed 
counts in segments of clusters of sets and their mirror images about an axis. The null distribution of the test is distribution-free and we tabulate it for values of $n(5 \leq n \leq 30)$. The exact null mean and null variance of the test are obtained. The asymptotic null distribution of the test turns out to be chi-square. The empirical findings suggest that the test performs reasonably well against various classes of asymmetric (nonexchangeable) bivariate distributions. We also compare the performance of the proposed test vis-à-vis its parametric and nonparametric competitors.

The rest of the paper is organized as follows. In Section 2, we discuss the motivation and rationality of the proposed test. The test procedure is described in Section 3. In Section 4, we tabulate the exact null distribution of the test statistics and also discuss its asymptotic distribution. The performance of the proposed test is evaluated in terms of simulated size and power, for a variety of symmetric and asymmetric bivariate distributions in Section 5. In Section 6, we evaluate the performance of the test with its parametric competitor (Bell and Haller [1]) and nonparametric competitors - signed rank test (Wilcoxon [8]) and Hollander's bivariate symmetry test. An illustrative example is provided in Section 7. Finally, some general comments are made in Section 8.

\section{The Rationale of Proposed Test}

Let $\left(X_{1}, Y_{1}\right), \ldots,\left(X_{n}, Y_{n}\right)$ be independent observations with common joint probability density function $f(x, y)$ and joint distribution function $F(x, y)$. Let $A \subset \mathfrak{R}^{2}, R(A)=\{(x, y):(y, x) \in A\}$. Then under $\mathrm{H}_{0}$, $P_{r}(A)=P_{r}\{R(A)\}$ and therefore, in a bivariate random sample of size $n$, the count of observations in $A$ and $R(A)$ are expected to be equal. Thus, a measure based on deviance of such counts for suitably formed partitions of sample space can be used to test $\mathrm{H}_{0}$ and this provides a strong motivation for the proposed test procedure. As an alternative to Hollander's $D_{n}$ test, we propose a test based on the transformed variables $U=X+Y$ and $V=X-Y$, given the bivariate sample 
$\left\{X_{i}, Y_{i}\right\}_{i=1}^{n}$. Further, the rationality of the proposed test is based on the Theorem 1 stated below, which establishes the equivalence between exchangeability of bivariate random variables $(X, Y)$ and symmetry of transformed bivariate random variables $(U, V)$ about $u$-axis. We recall the following two definitions:

Definition 2.1. A bivariate random variables $(X, Y)$ is said to be exchangeable if and only if the joint distribution function $F(x, y)$ is such that $F(x, y)=F(y, x)$ for all $(x, y) \in \mathfrak{R}^{2}$ (Lebesgue).

Definition 2.2. A bivariate random variables $(X, Y)$ is said to be the symmetric about $x$-axis if and only if the joint p.d.f, $f(x, y)$ is such that

$$
f(x, y)=f(x,-y) \text { for all }(x, y) \in \mathfrak{R}^{2} \text { (Lebesgue). }
$$

Next, we shall state the following two theorems and prove them in Appendix A. The Theorem 1 establishes that the hypothesis of exchangeability of $(X, Y)$ is equivalent to the hypothesis of symmetry of $(X+Y, X-Y)$ about $(x+y)$ axis and vice-versa. The Theorem 2 provides a basic probability result that will be used in the construction of the test in the next section.

Theorem 1. Let $(X, Y)$ be bivariate random variables with the joint p.d.f $f(x, y),(x, y) \in R^{2}$ and let $U=X+Y$ and $V=X-Y$. Then the distribution of $(U, V)$ is symmetric about u-axis if and only if $(X, Y)$ are exchangeable random variables.

Theorem 2. If $(U, V)$ is symmetric about u-axis, then for any arbitrary real numbers $a<b$, under $\mathrm{H}_{0}$,

$$
P_{r}(V>0 \mid a \leq U<b)=\frac{1}{2}=P_{r}(V<0 \mid a \leq U<b) .
$$




\section{The Test Statistics}

Let $\left(X_{1}, Y_{1}\right), \ldots,\left(X_{n}, Y_{n}\right)$ be independent observations from $F(x, y)$. Suppose that $U=X+Y$ and $V=X-Y$. Let the transformed bivariate samples $\left(U_{i}, V_{i}\right), i=1, \ldots, n$ be partitioned into $k$ clusters and the $j$-th cluster $A_{j}, j=1, \ldots, k$ be defined as $A_{j}=\left\{(u, v): d_{j-1}<u \leq d_{j}\right\}$, for some arbitrarily chosen real numbers $d_{1}<d_{2}<\ldots<d_{k-1}$, with $d_{0}=-\infty$ and $d_{k}=\infty$. Suppose that each cluster has two segments, $A_{j}^{+}, A_{j}^{-}$, one each on either side of the $u$-axis, defined by

$$
A_{j}^{+}=\left\{\left(u_{i}, v_{i}\right) \mid d_{j-1}<u_{i}<d_{j}, v_{i}>0\right\} \text { and } A_{j}^{-}=\left\{\left(u_{i}, v_{i}\right) \mid d_{j-1}<u_{i}<d_{j}, v_{i} \leq 0\right\} \text {, }
$$

for $j=1, \ldots, k, i=1, \ldots, n$. Note that segments $A_{1}^{-}, A_{2}^{-}, A_{3}^{-}$etc. are, respectively, the mirror images of the segments $A_{1}^{+}, A_{2}^{+}, A_{3}^{+}$etc. The proposed test is based on the counts of bivariate observations that fall in such suitably defined clusters. A natural and a practical way to construct clusters would be to define the $u$-axis dividers based on the order statistics of $U$ values in the transformed bivariate sample $(U, V)$ of size $n$. Let $U_{(i)}, i=1, \ldots, n$ be the $i$-th order statistics of the $U$ samples, $\left(U_{1}, \ldots, U_{n}\right)$ in the pair $\left\{U_{i}, V_{i}\right\}_{i=1}^{n}$ and let ' $m$ ' be a predetermined number and assume that $n=k m$, where $k=\frac{n}{m}$ is the number of clusters formed by the $(k-1)$ dividers $d_{1}, \ldots, d_{k-1}$, where $d_{j}=\frac{U_{(j m)}+U_{(j m+1)}}{2}, j=1, \ldots, k-1$. Then, we can easily see that

$$
A_{j}^{+}=\left\{\left(u_{i}, v_{i}\right) \mid d_{j-1}<u_{i}<d_{j}, v_{i}>0\right\} \text { and } A_{j}^{-}=\left\{\left(u_{i}, v_{i}\right) \mid d_{j-1}<u_{i}<d_{j}, v_{i} \leq 0\right\}
$$

for $j=1, \ldots, k, i=1, \ldots, n$, where $d_{0}=-\infty$ and $d_{k}=\infty$. Further, let

$$
P_{r}\left(A_{j}^{+}\right)=P_{r}\left[(U, V) \in A_{j}^{+}\right] \text {and } P_{r}\left(A_{j}^{-}\right)=P_{r}\left[(U, V) \in A_{j}^{-}\right], j=1, \ldots, k .
$$


Then as a consequence of the Theorem 2, under the null hypothesis (1), we have

$$
\mathrm{H}_{0 k}: P_{r}\left(A_{j}^{+}\right)=P_{r}\left(A_{j}^{-}\right), \quad \forall j=1, \ldots, k \text {. }
$$

Note that as $n \rightarrow \infty, k \rightarrow \infty,\left(d_{j}-d_{j-1}\right) \rightarrow 0, j=2, \ldots, k-1, d_{1} \rightarrow L$, $d_{k-1} \rightarrow U$, where $L$ and $U$ are lower and upper bounds of support of marginal distribution of $U$. Hence as $n \rightarrow \infty$, in a sense the sequence of null hypothesis $\left\{\mathrm{H}_{0 k}\right\}$ tends to $\mathrm{H}_{0}$.

Next, we shall let $N_{j}^{+}\left(N_{j}^{-}\right)$denote the number of observations in a random sample of size $n$ that belong to $A_{j}^{+}\left(A_{j}^{-}\right)$and $n_{j}^{+}\left(n_{j}^{-}\right)$be the observed value of $N_{j}^{+}\left(N_{j}^{-}\right), j=1, \ldots, k$. It can be noted that under $\mathrm{H}_{0}$, in each cluster, $n_{j}^{+}$and $n_{j}^{-}$are expected to be close to each other and therefore, we may use a criterion based on the observed deviance between these two counts aggregated suitably over all clusters. Thus, to test $\mathrm{H}_{0}$ against $\mathrm{H}_{1}$ one may use a measure of deviance given by

$$
M=\sum_{j=1}^{k} \frac{1}{n_{j}}\left(n_{j}^{+}-n_{j}^{-}\right)^{2},
$$

where $n_{j}=n_{j}^{+}+n_{j}^{-}$is the cluster $j$ marginal total. Finally, by noting that each $n_{j}$ is fixed and is equal to ' $m$ ', by construction, the application of the formula (4) leads to the test statistic

$$
M=\sum_{j=1}^{k} \frac{\left(n_{j}^{+}-n_{j}^{-}\right)^{2}}{m} .
$$

Clearly, the deviance measure (5) supports $\mathrm{H}_{0}$ when $M$ is smaller and therefore, can be used to test $\mathrm{H}_{0}$ versus $\mathrm{H}_{1}$. It is interesting to note that the statistic $M$ is essentially a count statistics and is proportional to the average of the variances of counts in $k$ clusters. 
The important question in the construction of the test statistic $M$ proposed here is the choice of the predetermined cluster size ' $m$ ' or the number of clusters ' $k$ '. As the sample size ' $n$ ' increases one can increase both ' $m$ ' and ' $k$ '. However, for $m$ fixed a sound asymptotic requires that as $n \rightarrow \infty, k \rightarrow \infty$, and as a consequence $\mathrm{H}_{0 k} \rightarrow \mathrm{H}_{0}$.

\section{Exact and Asymptotic Null Distributions}

To compute the exact null distribution, we note that $N_{j}^{+}, j=1, \ldots, k$ are independent and identically distributed binomial $(m, 1 / 2)$ random variables, under $\mathrm{H}_{0}$. Hence given, $n=m k$ we can easily obtain the null distribution of the test statistic $M$ given by (5). As an illustration, let us consider the case $n=5$. As $n$ is 5 , the only possible choice for $k$ and $m$ are 1 and 5 , respectively. Further, $N_{j}^{+}$s, $j=1, \ldots, 5$, are $0,1,2,3,4$ and 5 and the corresponding $N_{j}^{-}$'s, $j=1, \ldots, 5$, are 5, 4, 3, 2, 1 and 0 . Using (5), the possible values for $M$ are 5, 9/5, 1/5, and using binomial (5, 1/2)

distribution, the respective probabilities are $\frac{1}{2^{4}}, \frac{5}{2^{4}}$, and $\frac{10}{2^{4}}$. Similarly for the other sample sizes, the exact null distribution can be computed with all possible choices of $k, m$. We have computed the exact null distribution of the proposed test statistic for the sample sizes $n=5$ to 30 . However, when $n=m k$ has multiple factors, the null distribution for some chosen values of $k$ such as $k=2,3,4$ are tabulated in Table 7, given in Appendix B. For any other values of $n, k$, and $m$, one may get the MATLAB program which computes the null distribution from the authors.

The null mean and null variance of the test statistic $M$ are given in Theorem 3, while the asymptotic distribution is stated in Theorem 4 given below. The proofs are given in Appendix A. 
Theorem 3. The null mean and null variance of the test statistic $M$ are respectively given by

$$
\mu_{M}=k \text { and } \sigma_{M}^{2}=\frac{2 k(m-1)}{m}, m>1 .
$$

Theorem 4. Let $n=m k$, where $k$ is fixed. Then as $n \rightarrow \infty$,

$$
M=\sum_{j=1}^{k} \frac{\left(n_{j}^{+}-n_{j}^{-}\right)^{2}}{m} \stackrel{D}{\rightarrow} \chi_{k}^{2} .
$$

The decision rule based on the test statistic $M$ is given by: Reject $\mathrm{H}_{0}$ in favour of $\mathrm{H}_{1}$ if the observed $M \geq \chi_{k}^{2}(\alpha)$, where $\chi_{k}^{2}(\alpha)$ is such that $P_{r}\left(M \geq \chi_{k}^{2}(\alpha)\right)=\alpha, 0<\alpha<1$.

\section{Simulation Results}

In this section, we shall evaluate the empirical size and the empirical power of the proposed test based on small to moderate sample sizes $(15 \leq n \leq 60)$ for a variety of symmetric and asymmetric bivariate distributions. While calculating the simulated size and power of the proposed test we have used the exact null distribution for sample size $n(15 \leq n \leq 30)$ and asymptotic chi-square distribution for sample size $n$ (> 30). Further, as the test statistic $M$ defined in (5) takes the discrete values $t_{1}, \ldots, t_{k}$ with the probabilities $p_{1}, \ldots, p_{k}$, respectively, under $\mathrm{H}_{0}$, the test of size $\alpha$ is defined as

$$
\phi(x)= \begin{cases}1, & \text { if } M>c, \\ \gamma, & \text { if } M=c, \\ 0, & \text { if } M<c,\end{cases}
$$

where the constants $c$ and $\gamma$ are determined by $\alpha=E_{H_{0}}[\phi(X)]$. The empirical study was carried out for the combination of $(n, k, m)$ specified in Table 1, with $\alpha=0.05$ and number of Monte Carlo simulations being 
10000. Typical cases of sample sizes such as 'small' $(n=15,20)$, 'moderate' $(n=30,36)$, and 'large' $(n=50,60,75,100,150)$ were considered. The following bivariate symmetric and asymmetric populations were considered (i) bivariate normal $(0,0 ; 1,1 ; 0)(\mathrm{BVN})$, (ii) bivariate independent uniform $U(-1,-1)$, (iii) bivariate normal $(0,0 ; 1,1 ; \rho)$, with $\rho=0.1(0.1) 0.9$, and (iv) $X$ is standard normal, $Y$ is independent of $X$ and has epsilon-skew normal (ESN) distribution given by Mudholkar and Hutson [7]. The estimated simulated size and power of the proposed test $M$ are given in Table 2. The values reported in the table refer to the number of rejections for each case based on 10000 Monte Carlo simulations.

Table 1. Sample size with chosen $k$ and $m$

\begin{tabular}{|l|l|l|l|l|l|l|l|l|l|}
\hline$n$ (sample size) & 15 & 20 & 30 & 36 & 50 & 60 & 75 & 100 & 150 \\
\hline $\begin{array}{c}k \text { (number of } \\
\text { clusters) }\end{array}$ & 3 & 4 & 5 & 4 & $2,5,10$ & $2,3,4$ & 3,5 & $2,4,5,10$ & $2,3,5,10$ \\
\hline$m$ (cluster size) & 5 & 5 & 6 & 9 & $25,10,5$ & $30,20,15$ & 25,15 & $50,25,20,10$ & $75,50,30,15$ \\
\hline
\end{tabular}

From Tables 2 and 3, we may make the following broad conclusions:

(a) For bivariate independent $U(-1,1)$ distribution, the proposed test appears to be moderately conservative in most of the cases, even though the observed level of significance is within three sigma limits of the nominal level of significance. However, for bivariate independent normal distribution, the proposed test almost maintains the nominal level of significance in most of the cases provided the number of clusters is less than five.

(b) As regards the power of the proposed test, in the case of bivariate normal distribution, for small sample sizes, the power increases as the sample size, number of clusters and $|\rho|$, the skewness of the distribution increase. For moderate sample sizes, increase in power of the test is rapid as $|\rho|$ increases. For large sample sizes considered here, the power of the test rapidly approaches one when ever $|\rho|>0.6$. 
Table 2. Simulated size and power of $M$

\begin{tabular}{|c|c|c|c|c|c|c|c|c|c|c|c|}
\hline Distributions & $\begin{array}{c}n=15 \\
k=3\end{array}$ & $\begin{array}{c}n=20 \\
k=4\end{array}$ & $\begin{array}{c}n=30 \\
k=5\end{array}$ & $\begin{array}{c}n=36, \\
k=4\end{array}$ & $\begin{array}{c}n=50, \\
k=2\end{array}$ & $\begin{array}{c}n=50 \\
k=5\end{array}$ & $\begin{aligned} n & =50, \\
k & =10\end{aligned}$ & $\begin{array}{c}n=60, \\
k=2\end{array}$ & $\begin{array}{c}n=60, \\
k=3\end{array}$ & $\begin{array}{c}n=60 \\
k=4\end{array}$ & $\begin{array}{c}n=75, \\
k=3\end{array}$ \\
\hline$X, Y: U(-1,1)$ & 0.0622 & 0.0488 & 0.0467 & 0.0469 & 0.0452 & 0.0435 & 0.0241 & 0.0533 & 0.0466 & 0.0433 & 0.0455 \\
\hline $\begin{array}{c}X, Y: \text { Standard } \\
\text { BVN }\end{array}$ & 0.050 & 0.050 & 0.0513 & 0.050 & 0.0459 & 0.0429 & 0.0223 & 0.0544 & 0.0506 & 0.0451 & 0.0457 \\
\hline $\begin{array}{c}X, Y: \text { BVN } \\
\rho=0.1\end{array}$ & 0.0535 & 0.0508 & 0.0571 & 0.0595 & 0.0588 & 0.0509 & 0.0318 & 0.0726 & 0.0660 & 0.0547 & 0.0660 \\
\hline $\begin{array}{c}X, Y: \text { BVN, } \\
\rho=0.2\end{array}$ & 0.0688 & 0.0655 & 0.0759 & 0.0905 & 0.1041 & 0.0860 & 0.0501 & 0.1346 & 0.1223 & 0.1078 & 0.1398 \\
\hline $\begin{array}{c}X, Y: \text { BVN, } \\
\rho=0.3\end{array}$ & 0.0876 & 0.0929 & 0.1164 & 0.1402 & 0.2020 & 0.1750 & 0.0833 & 0.2464 & 0.2501 & 0.2263 & 0.2900 \\
\hline $\begin{array}{c}X, Y: \text { BVN } \\
\rho=0.4\end{array}$ & 0.1137 & 0.1343 & 0.1954 & 0.2504 & 0.3332 & 0.3049 & 0.1580 & 0.4336 & 0.4451 & 0.4037 & 0.5305 \\
\hline $\begin{array}{c}X, Y: \text { BVN } \\
\rho=0.5\end{array}$ & 0.1728 & 0.2041 & 0.3062 & 0.4030 & 0.5371 & 0.5140 & 0.2975 & 0.6478 & 0.6640 & 0.6355 & 0.7786 \\
\hline $\begin{array}{c}X, Y: \text { BVN, } \\
\rho=0.6\end{array}$ & 0.2460 & 0.3042 & 0.4788 & 0.6093 & 0.7478 & 0.7532 & 0.5157 & 0.8405 & 0.8682 & 0.8566 & 0.9382 \\
\hline $\begin{array}{c}X, Y: \text { BVN } \\
\rho=0.7\end{array}$ & 0.3512 & 0.4677 & 0.6832 & 0.8095 & 0.9049 & 0.9198 & 0.7607 & 0.9549 & 0.9737 & 0.9718 & 0.9928 \\
\hline $\begin{array}{c}X, Y: \text { BVN } \\
\rho=0.8\end{array}$ & 0.5198 & 0.6687 & 0.8783 & 0.9528 & 0.9812 & 0.9901 & 0.9537 & 0.9961 & 0.9984 & 0.9993 & 0.9998 \\
\hline $\begin{array}{c}X, Y: \text { BVN } \\
\rho=0.9\end{array}$ & 0.7328 & 0.8896 & 0.9886 & 0.9986 & 0.9998 & 0.9999 & 0.9990 & 0.9999 & 1.000 & 1.000 & 1.000 \\
\hline $\begin{array}{c}X: N(0,1) \\
Y: \operatorname{ESN}(\varepsilon=0.7)\end{array}$ & 0.4452 & 0.5442 & 0.9284 & 0.9748 & 0.9997 & 0.9943 & 0.9669 & 0.9999 & 0.9997 & 0.9999 & 1.000 \\
\hline
\end{tabular}


Table 3. Simulated size and power of $M$

\begin{tabular}{|c|c|c|c|c|c|c|c|c|c|}
\hline Distributions & $\begin{array}{c}n=75, \\
k=5\end{array}$ & $\begin{array}{c}n=100, \\
k=2\end{array}$ & $\begin{array}{c}n=100, \\
k=4\end{array}$ & $\begin{array}{c}n=100, \\
k=5\end{array}$ & $\begin{array}{c}n=100, \\
k=10\end{array}$ & $\begin{array}{c}n=150, \\
k=2\end{array}$ & $\begin{array}{c}n=150, \\
k=3\end{array}$ & $\begin{array}{c}n=150, \\
k=5\end{array}$ & $\begin{array}{c}n=150, \\
k=10\end{array}$ \\
\hline$X, Y: U(-1,1)$ & 0.0369 & 0.0499 & 0.0521 & 0.0459 & 0.0452 & 0.0542 & 0.0546 & 0.0432 & 0.0408 \\
\hline $\begin{array}{c}X, Y: \text { Standard } \\
\text { BVN }\end{array}$ & 0.0410 & 0.0498 & 0.0466 & 0.0437 & 0.0409 & 0.0548 & 0.0515 & 0.0459 & 0.0375 \\
\hline $\begin{array}{c}X, Y: \mathrm{BVN}, \\
\rho=0.1\end{array}$ & 0.0584 & 0.0737 & 0.0778 & 0.0692 & 0.0579 & 0.1033 & 0.0963 & 0.0909 & 0.0689 \\
\hline $\begin{array}{c}X, Y: \text { BVN } \\
\rho=0.2\end{array}$ & 0.1168 & 0.1773 & 0.1782 & 0.1536 & 0.1188 & 0.2736 & 0.2878 & 0.2337 & 0.1686 \\
\hline $\begin{array}{c}X, Y: \text { BVN } \\
\rho=0.3\end{array}$ & 0.2531 & 0.3705 & 0.3755 & 0.3657 & 0.2629 & 0.5686 & 0.6038 & 0.5534 & 0.4254 \\
\hline $\begin{array}{c}X, Y: \text { BVN } \\
\rho=0.4\end{array}$ & 0.4807 & 0.6255 & 0.6702 & 0.6409 & 0.5096 & 0.8331 & 0.8721 & 0.8591 & 0.7466 \\
\hline $\begin{array}{c}X, Y: \text { BVN } \\
\rho=0.5\end{array}$ & 0.7346 & 0.8500 & 0.8964 & 0.8830 & 0.7904 & 0.9728 & 0.9833 & 0.9817 & 0.9514 \\
\hline $\begin{array}{c}X, Y: \text { BVN } \\
\rho=0.6\end{array}$ & 0.9246 & 0.9707 & 0.9884 & 0.9847 & 0.9617 & 0.9977 & 0.9995 & 0.9995 & 0.9988 \\
\hline $\begin{array}{c}X, Y: \text { BVN } \\
\rho=0.7\end{array}$ & 0.9920 & 0.9985 & 0.9997 & 0.9996 & 0.9981 & 1.000 & 1.000 & 1.000 & 1.000 \\
\hline $\begin{array}{c}X, Y: \text { BVN } \\
\rho=0.8\end{array}$ & 0.9999 & 1.000 & 1.000 & 1.000 & 1.000 & 1.000 & 1.000 & 1.000 & 1.000 \\
\hline $\begin{array}{c}X, Y: \text { BVN } \\
\rho=0.9\end{array}$ & 1.000 & 1.000 & 1.000 & 1.000 & 1.000 & 1.000 & 1.000 & 1.000 & 1.000 \\
\hline$X: N(0,1)$ & 1.000 & 1.000 & 1.000 & 1.000 & 1.000 & 1.000 & 1.000 & 1.000 & 1.000 \\
\hline$Y: \operatorname{ESN}(\varepsilon=0.7)$ & & & & & & & & & \\
\hline
\end{tabular}

(c) For the epsilon-skew-normal bivariate distribution, the power of the proposed test increases rapidly as the sample size increases. Further, as in the case of bivariate normal distribution, the increase in power is significantly associated with increase in $|\varepsilon|$, where $\varepsilon$ is the skewness parameter.

Based on the above findings, we see that for small to large sample sizes, the proposed test performs well in terms of simulated size and empirical power for the selected family of populations conforming to the null and alternative hypotheses of interest. Further, it is seen that one may take the number of clusters in the range of two to four and such tests have reasonably good increasing power in the class of distributions considered here. 


\section{Comparison with Competitors}

In the following section, we shall conduct some Monte Carlo power comparisons of the exact $M$ test with Hollander's test $D$ and two other tests considered by Hollander [3].

(i) Bell and Haller [1] normal theory test. Let $V_{i}=Y_{i}-X_{i}$ and $U_{i}=X_{i}+Y_{i}$. Assume $F$ is bivariate normal. Then $\mathrm{H}_{0}$ is equivalent to having $E(V)=0$ and $\operatorname{Cov}(V, U)=0$. Set

$$
\left|G_{1}\right|=\bar{V} n^{\frac{1}{2}} s_{v}^{-1}, G_{2}=r(V, U)(n-2)^{\frac{1}{2}}\left\{1-r^{2}(V, U)\right\}^{-\frac{1}{2}}
$$

where $\bar{V}=\sum V_{i} / n, s_{v}^{2}=\sum\left(V_{i}-\bar{V}\right)^{2} / n$ and $r(V, U)=n^{-1} \sum\left(V_{i}-\bar{V}\right)$ $\left(U_{i}-\bar{U}\right) / s_{v} s_{u}$. Under $\mathrm{H}_{0}, G_{1}$ and $G_{2}$ are independent and have Student's $t$-distribution with $(n-1)$ and $(n-2)$ degrees of freedom, respectively. Bell and Haller [1] point out that $G_{1}$ is directed toward $E(V)=0$ and $G_{2}$ should be good for testing $\operatorname{Cov}(V, U)=0$. Let $t(\alpha, n)$ denote the upper $\alpha$-th percentile of a $t$-distribution with $n$ degrees of freedom. The test proposed in Theorem 4.3 of the Bell and Haller [1] rejects $\mathrm{H}_{0}$ if

$$
\left|G_{1}\right|>t\left(\frac{1}{2} \alpha_{1}, n-1\right) \quad \text { or } \quad\left|G_{2}\right|>t\left(\frac{1}{2} \alpha_{2}, n-2\right)
$$

and has size $\alpha=\alpha_{1}+\alpha_{2}-\alpha_{1} \alpha_{2}$.

(ii) Wilcoxon signed rank test. Let $R\left(\left|V_{i}\right|\right)$ denote the rank of $\left|V_{i}\right|$ in the joint ranking from least to greatest of $\left|V_{1}\right|, \ldots,\left|V_{n}\right|$. Let

$$
W^{+}=\sum_{i=1}^{n} R\left(\left|V_{i}\right|\right) \psi_{i},
$$


where $\psi_{i}=1$ if $V_{i}>0,=0$ otherwise. The two-sided Wilcoxon signed rank test rejects for large values of $\max \left\{W^{+}, \frac{1}{2} n(n+1)-W^{+}\right\}$. For $F$ 's not satisfying $\mathrm{H}_{0}$ but having the marginal distribution of $V_{i}$ continuous and symmetric about 0 , this test will have power equal to size.

Table 4 compares the power of the Bell-Haller [1] test defined by (8), the two sided Wilcoxon signed rank test, the Hollander conditional test based on $n D_{n}$, and the proposed test $M$, for bivariate normal $\left(\mu_{1}, \mu_{2} ; \sigma_{1}, \sigma_{2} ; \rho\right)$ populations with $\mu_{1}=0, \sigma_{1}=1, \mu_{2}=0, \frac{1}{2}, 1,2, \sigma_{2}=1, \rho=0, \frac{1}{2}$, and sample size $n=5(\alpha=0.625,0.1250)$. The $\alpha_{1}, \alpha_{2}$ values of (8) were set at $\alpha_{1}=\alpha_{2}=1-\sqrt{(1-\alpha)}$. A partial check on the Monte Carlo values is provided by noting that power should equal size for all these tests at $\mu_{2}=0$. 
Table 4. Estimated power of four tests for bivariate normal populations, $\mu_{1}=0, \sigma_{1}=\sigma_{2}=1 ; n=5$ (1000 simulations)

\begin{tabular}{|c|c|c|c|c|c|c|c|c|c|c|c|c|c|c|c|c|}
\hline Test & $\mathrm{BH}$ & $\mathrm{W}$ & D & M & $\mathrm{BH}$ & W & D & $\mathrm{M}$ & $\mathrm{BH}$ & $\mathrm{W}$ & D & $\mathrm{M}$ & $\mathrm{BH}$ & $\mathrm{W}$ & D & M \\
\hline$\mu_{2}$ & \multicolumn{4}{|c|}{0} & \multicolumn{4}{|c|}{0.5} & \multicolumn{4}{|c|}{1} & \multicolumn{4}{|c|}{2} \\
\hline$(\alpha, \rho)$ & & & & & & & & & & & & & & & & \\
\hline$(0.0625,0)$ & 0.074 & 0.061 & 0.057 & 0.058 & 0.113 & 0.113 & 0.109 & 0.154 & 0.247 & 0.258 & 0.196 & 0.265 & 0.638 & 0.640 & 0.493 & 0.891 \\
\hline$(0.0625,0.5)$ & 0.086 & 0.070 & 0.058 & 0.063 & 0.174 & 0.173 & 0.126 & 0.160 & 0.407 & 0.433 & 0.313 & 0.433 & 0.909 & 0.901 & 0.743 & 0.903 \\
\hline$(0.125,0)$ & 0.154 & 0.119 & 0.114 & 0.117 & 0.214 & 0.214 & 0.174 & 0.240 & 0.381 & 0.401 & 0.329 & 0.508 & 0.811 & 0.849 & 0.700 & 0.914 \\
\hline$(0.125,0.5)$ & 0.163 & 0.137 & 0.121 & 0.118 & 0.295 & 0.306 & 0.249 & 0.245 & 0.588 & 0.638 & 0.503 & 0.492 & 0.965 & 0.982 & 0.895 & 0.918 \\
\hline
\end{tabular}

BH: test of Bell \& Haller [1], W: Wilcoxon [8]; D: Hollander [3], M: proposed test. 
Table 5 compares the powers for bivariate exponential populations with distribution function of the form

$$
F(x, y)=F_{1}(x) F_{2}(y)\left[1+\Delta\left\{1-F_{1}(x)\right\}\left\{1-F_{2}(y)\right\}\right](-1 \leq \Delta \leq 1),
$$

where $F_{1}(x)=1-e^{-x}(0<x<\infty)$ and $F_{2}(x)=F_{1}\left(x-\mu_{2}\right)$. The system (10) was considered here as done by Hollander [3]. We investigate the cases $\mu_{2}=0, \frac{1}{2}, 1,2$, and $\Delta=0,0.8$. The value $\Delta=0$ corresponds to independent exponentials, where as the correlation coefficient between $X$ and $Y$ is 0.2 for $\Delta=0.8$. The power should equal size for $W$ and $D$ at $\mu_{2}=0$. The $n$ 's sand $\alpha$ 's are the same for Table 4 . All entries in Tables 3 and 4 are based on 1000 simulations. 
Table 5. Estimated power of four tests for bivariate exponential populations; $n=5$ (1000 simulations)

\begin{tabular}{llllllllllllll}
\hline Test & $\mathrm{BH}$ & $\mathrm{W}$ & $\mathrm{D}$ & $\mathrm{M}$ & $\mathrm{W}$ & $\mathrm{D}$ & $\mathrm{M}$ & $\mathrm{W}$ & $\mathrm{D}$ & $\mathrm{M}$ & $\mathrm{W}$ & $\mathrm{D}$ & $\mathrm{M}$ \\
\hline$\mu_{2}$ & \multicolumn{1}{c}{0} & & & 0.5 & & & 1 & & & 2 & \\
\hline$(\alpha, \Delta)$ & & & & & & & & & & & & & \\
$(0.0625,0)$ & 0.133 & 0.065 & 0.060 & 0.059 & 0.160 & 0.141 & 0.171 & 0.345 & 0.277 & 0.357 & 0.698 & 0.534 & 0.694 \\
$(0.0625,0.8)$ & 0.140 & 0.070 & 0.056 & 0.139 & 0.197 & 0.173 & 0.358 & 0.436 & 0.363 & 0.552 & 0.745 & 0.626 & 0.812 \\
$(0.125,0)$ & 0.233 & 0.125 & 0.119 & 0.119 & 0.269 & 0.242 & 0.192 & 0.513 & 0.454 & 0.438 & 0.861 & 0.738 & 0.75 \\
$(0.125,0.8)$ & 0.248 & 0.119 & 0.111 & 0.262 & 0.324 & 0.298 & 0.407 & 0.602 & 0.558 & 0.602 & 0.882 & 0.798 & 0.833 \\
\hline
\end{tabular}

BH: test of Bell \& Haller [1], W: Wilcoxon [8]; D: Hollander [3], M: proposed test. 
From Tables 4 and 5, we observe that the proposed test is powerful in detecting location changes in both the distributions. For example, when $F(x, y)$ is bivariate normal, it does better than Hollander's $D$ test, and is as good as or better than the Wilcoxon $W$ test in several cases. A similar picture emerges while $F(x, y)$ is bivariate exponential. For reasons suggested by Hollander [3], we have also not included the estimates of the power of the Bell-Haller test for exponential populations when $\mu_{2} \neq 0$.

\section{An Illustrative Example}

We illustrate the computation of the observed test statistics $M$ in an example based on $n=7$ data pairs given by Hollander [4]. Hilton [2] also used this example and provided an alternative way to calculate the observed value of the Hollander test statistic. In this example, as in Hollander [4], $x$ and $y$ represent inulin clearance of kidney donors and recipients, respectively.

Table 6. Inulin clearance of Living Donors and recipients of their kidneys

\begin{tabular}{|c|c|c|c|c|c|c|c|}
\hline Patient $i$ & 1 & 2 & 3 & 4 & 5 & 6 & 7 \\
\hline$x_{i}$ & 61.4 & 63.3 & 63.7 & 80.0 & 77.3 & 84.0 & 105.0 \\
\hline$y_{i}$ & 70.8 & 89.2 & 65.8 & 67.1 & 87.3 & 85.1 & 88.1 \\
\hline
\end{tabular}

We have $n=7$, so that $k=1, m=7$. We find $u_{i}=x_{i}+y_{i}$ and $v_{i}=x_{i}-y_{i}, i=1, \ldots, n$. Thus,

$u_{1}=132.2, u_{2}=152.5, u_{3}=129.5, u_{4}=147.1, u_{5}=164.6, u_{6}=169.1, u_{7}=193.1$

$v_{1}=-9.4, \quad v_{2}=-25.9, v_{3}=-2.1, v_{4}=12.9, \quad v_{5}=-10, \quad v_{6}=-1.1, v_{7}=16.9$.

Thus we have $n_{1}^{+}=2, n_{1}^{-}=5$, so that from (5), we get $M=\frac{(2-5)^{2}}{7}=\frac{9}{7}$.

Referring to the Table 6 of exact null distribution in Appendix, we have the exact $p$-value, $p=P_{r}\left(M \geq \frac{9}{7}\right)=0.4531$. From Hilton [2], we find 
that using the Hollander test for bivariate symmetry, the observed statistic is $h\left(s^{*}\right)=T^{\prime \prime} T=7$ and the exact and asymptotic (using linear interpolation) $p$-values are $p=0.9375$ and $\hat{p}=0.460$. It is clear that the lowest level at which we can reject the hypothesis of symmetry using a non randomized test based on $M$ is 0.4531 , while it is 0.9375 for the Hollander test. For Bell and Haller's test, we have

$$
\left|G_{1}\right|=0.486, \quad\left|G_{2}\right|=0.967
$$

and with $\alpha_{1}=\alpha_{2}=1-\sqrt{1-0.05}=0.0253, t(0.0127,6)=3.018$, $t(0.0127,5)=3.222$; thus not satisfying both the inequalities in (8). For the Wilcoxon test, we have

$$
\max \left\{W^{+},\{7(7+1) / 2\}-W^{+}\right\}=17,
$$

which is significant at level 0.766 . Thus all the four tests indicate that there is no reason to believe that the clearance capacity of the donor and recipient after the kidney transplant was done differ significantly.

\section{Conclusion}

In this paper, we revisit the classical problem of testing for bivariate symmetry. A new nonparametric test for bivariate symmetry is proposed. The proposed test is primarily based on count statistics and is very simple to carry out unlike its competitors such as Hollander [3]. The exact null distribution of the test statistic is computed for different sample sizes. For large sample, the test statistic has an asymptotic chisquare distribution. Monte Carlo study indicates that the proposed test is quite reasonable in terms of simulated size and empirical power. The proposed test is compared with the parametric Bell and Haller [1] test, the Hollander [3] test and the Wilcoxon signed rand test. The simulation study indicates that the new test is better than Hollander's $D$ test and as good as signed rank test $W$. Finally, the 'count statistics approach'

suggested here can be further improved upon by taking into account the metric distance of the $v$-observations from the $u$-axis within each cluster. 


\section{References}

[1] C. B. Bell and H. S. Haller, Bivariate symmetry tests: Parametric and nonparametric, Annals of Mathematical Statistics 40(1) (1969), 259-269.

[2] J. F. Hilton, A new asymptotic distribution for Hollander's bivariate symmetry statistic. Technical Report \# 53, Department of Epidemiology \& Biostatistics, University of California, San Francisco, 1996.

[3] M. Hollander, A nonparametric test for bivariate symmetry, Biometrika 58(1) (1971), 203-212.

[4] M. Hollander, Nonparametric Statistical Methods, John Wiley \& Sons, New York, 1973.

[5] J. L. Kepner and R. H. Randles, Comparison of tests for bivariate symmetry versus location and / or scale alternatives, Commun. Statist.-Theor. Meth. 13 (1984), 915-930.

[6] J. A. Koziol, A test for bivariate symmetry based on the empirical distribution function, Commun. Statist.-Theor. Meth. A8 (1979), 207-221.

[7] G. S. Mudholkar and A. D. Hutson, The epsilon-skew-normal distribution for analyzing near-normal data, Journal of Statistical Planning and Inference 83(2) (2000), 291-309.

[8] F. Wilcoxon, Individual comparisons by ranking methods, Biometrics 1 (1945), 80-83. 


\section{Appendix A}

Proof of Theorem 1. To prove the if part, let $(X, Y)$ be exchangeable and $\phi\left(t_{1}, t_{2}\right), g(u, v)$, respectively, be the joint c.f. and p.d.f. of $(U, V)$. Then consider,

$$
\begin{aligned}
\phi_{U, V}\left(t_{1}, t_{2}\right) & =\exp \left(i t_{1} U+i t_{2} V\right) \\
& =\exp \left\{i t_{1}(X+Y)+i t_{2}(X-Y)\right\} \\
& =\exp \left\{i t_{1}(Y+X)-i t_{2}(Y-X)\right\}, \text { because } X \text { and } Y \text { are exchangeable } \\
& =\phi_{U, V}\left(t_{1},-t_{2}\right) \\
& =\phi_{U,-V}\left(t_{1}, t_{2}\right) .
\end{aligned}
$$

Thus $(U, V)$ and $(U,-V)$ have the same joint distribution and hence $g(u, v)=g(u,-v)$.

Now to prove the only if part, let $g(u, v)=g(u,-v)$. Let $\psi_{X, Y}\left(t_{1}, t_{2}\right)$ be the joint c.f. of $(X, Y)$. Then we have, since

$$
\begin{aligned}
\psi_{X, Y}\left(t_{1}, t_{2}\right) & =E\left[\exp \left(i t_{1} X+i t_{2} Y\right)\right] \\
& =E\left[\exp \left\{i t_{1}\left(\frac{U+V}{2}\right)+i t_{2}\left(\frac{U-V}{2}\right)\right\}\right] \\
& =E\left[\exp \left\{i t_{1}\left(\frac{U-V}{2}\right)+i t_{2}\left(\frac{U+V}{2}\right)\right\}\right], \text { since } g(u, v)=g(u,-v) \\
& =E\left[\exp \left(i t_{1} Y+i t_{2} X\right)\right] \\
& =\psi_{Y, X}\left(t_{1}, t_{2}\right) .
\end{aligned}
$$

Thus $X$ and $Y$ are exchangeable. This completes the proof.

Proof of Theorem 2. Consider,

$$
\begin{aligned}
P_{r}(V>0 \mid a \leq U<b)= & \frac{P_{r}(V>0, a \leq U<b)}{P_{r}(a \leq U<b)} \\
& =\frac{\int_{a}^{b} \int_{0}^{\infty} g(u, v) d v d u}{P_{r}(a \leq U<b)}
\end{aligned}
$$




$$
\begin{aligned}
& \int_{a}^{b} \int_{0}^{\infty} g(u,-v) d v d u \\
= & \frac{\int_{a} \int_{-\infty}(a \leq U<b)}{P_{r}} g(u, t) d t d u \\
= & \frac{P_{r}(a \leq U<b)}{0} g(u, v)=g(u,-v) . \\
= & P_{r}(V<0 \mid a \leq U<b) .
\end{aligned}
$$

This completes the proof.

Proof of Theorem 3. First it can be easily shown that the measure of deviance (5) can be equivalently expressed as

$$
M=\frac{4}{m} \sum_{j=1}^{k}\left(n_{j}^{+}-\frac{m}{2}\right)^{2} .
$$

Next consider,

$$
\begin{aligned}
\mu_{M} & =E_{H_{0}}(M) \\
& =E_{H_{0}}\left(\frac{4}{m} \sum_{j=1}^{k}\left(n_{j}^{+}-\frac{m}{2}\right)^{2}\right) \\
& =\frac{4}{m} \sum_{j=1}^{k} V_{H_{0}}\left(n_{j}^{+}\right) \\
& =k, \text { since } V_{H_{0}}\left(n_{j}^{+}\right)=\frac{m}{4} .
\end{aligned}
$$

Further,

$$
\begin{aligned}
\sigma_{M}^{2} & =V_{H_{0}}(M) \\
& =V_{H_{0}}\left(\frac{4}{m} \sum_{j=1}^{k}\left(n_{j}^{+}-\frac{m}{2}\right)^{2}\right)
\end{aligned}
$$




$$
\begin{aligned}
& =\frac{16}{m^{2}} \sum_{j=1}^{k}\left[E_{H_{0}}\left\{n_{j}^{+}-\frac{m}{2}\right\}^{4}-E^{2} H_{0}\left\{n_{j}^{+}-\frac{m}{2}\right\}^{2}\right] \\
& =\frac{16}{m^{2}} \sum_{j=1}^{k}\left[\mu_{4}\left(H_{0}\right)-\mu_{2}^{2}\left(H_{0}\right)\right] \\
& =\frac{16}{m^{2}} \sum_{j=1}^{k}\left[\frac{m}{4}\left\{1+\frac{3}{4}(m-2)\right\}-\left(\frac{m}{2}\right)^{2}\right] \\
& =\frac{2 k(m-1)}{m}, m>1 .
\end{aligned}
$$

This completes the proof.

Proof of Theorem 4. First, it can be easily shown that under the null hypothesis, $E\left(N_{j}^{+}\right)=E\left(N_{j}^{-}\right)=\frac{m}{2}, j=1, \ldots, k$, where $N_{j}=N_{j}^{+}+N_{j}^{-}=m$ is fixed by virtue of construction. Next, consider,

$$
\begin{aligned}
M & =\frac{4}{m} \sum_{j=1}^{k}\left(n_{j}^{+}-\frac{m}{2}\right)^{2} \\
& =\sum_{j=1}^{k} Z_{j}^{2}, \text { where } Z_{j}=\frac{\left(n_{j}^{+}-\frac{m}{2}\right)}{\sqrt{\frac{m}{4}}}, j=1, \ldots, k .
\end{aligned}
$$

By recalling that, under $\mathrm{H}_{0}, N_{j}^{+} \sim B$ in $\left(m, \frac{1}{2}\right)$, so that for large $Z_{j} \sim N(0,1)$ and $Z_{j}^{2} \sim \chi_{(1)}^{2}$. Finally, by virtue of independence of $N_{j}^{+}$, s, it follows that

$$
M=\sum_{j=1}^{k} \frac{\left(n_{j}^{+}-n_{j}^{-}\right)}{m}=\sum_{j=1}^{k} Z_{j}^{2} \sim \chi_{(k)}^{2} .
$$

This completes the proof. 


\section{Appendix B}

Table 7. Small samples exact null distribution of the test statistic $M$ (Left half of the table)

\begin{tabular}{|c|c|c|c|c|c|c|c|c|c|c|}
\hline$n$ & $m$ & & & & & & & & & \\
\hline 5 & 5 & $\begin{array}{c}M \\
\mathrm{p}\end{array}$ & $\begin{array}{c}5 \\
0.0625\end{array}$ & $\begin{array}{c}1.8 \\
0.3125\end{array}$ & $\begin{array}{c}0.2 \\
0.6250\end{array}$ & & & & & \\
\hline 6 & 3 & $\begin{array}{c}M \\
\mathrm{p}\end{array}$ & $\begin{array}{c}6 \\
0.0625\end{array}$ & $\begin{array}{c}10 / 3 \\
0.3750\end{array}$ & $\begin{array}{c}2 / 3 \\
0.5625\end{array}$ & & & & & \\
\hline 7 & 7 & $\begin{array}{c}M \\
\mathrm{p}\end{array}$ & $\begin{array}{c}7 \\
0.0156 \\
\end{array}$ & $\begin{array}{c}25 / 7 \\
0.1094\end{array}$ & $\begin{array}{c}9 / 7 \\
0.3281 \\
\end{array}$ & $\begin{array}{c}1 / 7 \\
0.5469\end{array}$ & & & & \\
\hline 8 & 4 & $\begin{array}{c}M \\
\mathrm{p}\end{array}$ & $\begin{array}{c}8 \\
0.0156 \\
\end{array}$ & $\begin{array}{c}5 \\
0.1250 \\
\end{array}$ & $\begin{array}{c}4 \\
0.0938 \\
\end{array}$ & $\begin{array}{c}2 \\
0.2500 \\
\end{array}$ & $\begin{array}{c}1 \\
0.3750 \\
\end{array}$ & $\begin{array}{c}0 \\
0.1406 \\
\end{array}$ & & \\
\hline 9 & 3 & $\begin{array}{c}M \\
\mathrm{p}\end{array}$ & $\begin{array}{c}9 \\
0.0156 \\
\end{array}$ & $\begin{array}{c}19 / 3 \\
0.1406\end{array}$ & $\begin{array}{c}11 / 3 \\
0.4219 \\
\end{array}$ & $\begin{array}{c}1 \\
0.4219 \\
\end{array}$ & & & & \\
\hline 10 & 5 & $\begin{array}{c}M \\
\mathrm{p}\end{array}$ & $\begin{array}{c}10 \\
0.0039 \\
\end{array}$ & $\begin{array}{c}34 / 5 \\
0.0391 \\
\end{array}$ & $\begin{array}{c}26 / 5 \\
0.0781 \\
\end{array}$ & $\begin{array}{c}18 / 5 \\
0.0977\end{array}$ & $\begin{array}{c}2 \\
0.3906 \\
\end{array}$ & $\begin{array}{c}2 / 5 \\
0.3906 \\
\end{array}$ & & \\
\hline 11 & 11 & $\begin{array}{c}M \\
\mathrm{p} \\
\end{array}$ & $\begin{array}{c}11 \\
0.001 \\
\end{array}$ & $\begin{array}{c}81 / 11 \\
0.0107\end{array}$ & $\begin{array}{c}49 / 11 \\
0.0537 \\
\end{array}$ & $\begin{array}{c}25 / 11 \\
0.1611 \\
\end{array}$ & $\begin{array}{c}9 / 11 \\
0.3223 \\
\end{array}$ & $\begin{array}{c}1 / 11 \\
0.4512 \\
\end{array}$ & & \\
\hline 12 & 3 & $\begin{array}{c}M \\
\mathrm{p}\end{array}$ & $\begin{array}{c}12 \\
0.0039\end{array}$ & $\begin{array}{c}28 / 3 \\
0.0469\end{array}$ & $\begin{array}{c}20 / 3 \\
0.2109\end{array}$ & $\begin{array}{c}4 \\
0.4219 \\
\end{array}$ & $\begin{array}{c}4 / 3 \\
0.3164 \\
\end{array}$ & & & \\
\hline & 4 & $\begin{array}{l}M \\
\mathrm{p} \\
\end{array}$ & $\begin{array}{c}12 \\
0.002 \\
\end{array}$ & $\begin{array}{c}9 \\
0.0234 \\
\end{array}$ & $\begin{array}{c}8 \\
0.0176 \\
\end{array}$ & $\begin{array}{c}6 \\
0.0938 \\
\end{array}$ & $\begin{array}{c}5 \\
0.1406 \\
\end{array}$ & $\begin{array}{c}4 \\
0.0527 \\
\end{array}$ & $\begin{array}{c}3 \\
0.125 \\
\end{array}$ & $\begin{array}{c}2 \\
0.2813 \\
\end{array}$ \\
\hline & 6 & $\begin{array}{c}M \\
\mathrm{p}\end{array}$ & $\begin{array}{c}12 \\
0.001 \\
\end{array}$ & $\begin{array}{c}52 / 6 \\
0.0117 \\
\end{array}$ & $\begin{array}{c}40 / 6 \\
0.0293 \\
\end{array}$ & $\begin{array}{c}6 \\
0.0195 \\
\end{array}$ & $\begin{array}{c}32 / 6 \\
0.0352 \\
\end{array}$ & $\begin{array}{c}20 / 6 \\
0.1758 \\
\end{array}$ & $\begin{array}{c}16 / 6 \\
0.1172 \\
\end{array}$ & $\begin{array}{c}8 / 6 \\
0.2197 \\
\end{array}$ \\
\hline 13 & 13 & $\begin{array}{c}M \\
\mathrm{p} \\
\end{array}$ & $\begin{array}{c}13 \\
0.0002 \\
\end{array}$ & $\begin{array}{l}121 / 13 \\
0.0032\end{array}$ & $\begin{array}{l}81 / 13 \\
0.019 \\
\end{array}$ & $\begin{array}{c}49 / 13 \\
0.0698 \\
\end{array}$ & $\begin{array}{c}25 / 13 \\
0.1746 \\
\end{array}$ & $\begin{array}{c}9 / 13 \\
0.3143 \\
\end{array}$ & $\begin{array}{c}1 / 13 \\
0.419 \\
\end{array}$ & \\
\hline 14 & 7 & $\begin{array}{c}M \\
\mathrm{p}\end{array}$ & $\begin{array}{c}14 \\
0.0002\end{array}$ & $\begin{array}{c}74 / 7 \\
0.0034\end{array}$ & $\begin{array}{c}58 / 7 \\
0.0103\end{array}$ & $\begin{array}{c}50 / 7 \\
0.029\end{array}$ & $\begin{array}{c}34 / 7 \\
0.0718\end{array}$ & $\begin{array}{c}26 / 7 \\
0.1196\end{array}$ & $\begin{array}{c}18 / 7 \\
0.1077\end{array}$ & $\begin{array}{c}10 / 7 \\
0.3589\end{array}$ \\
\hline
\end{tabular}


(Right half of the table)

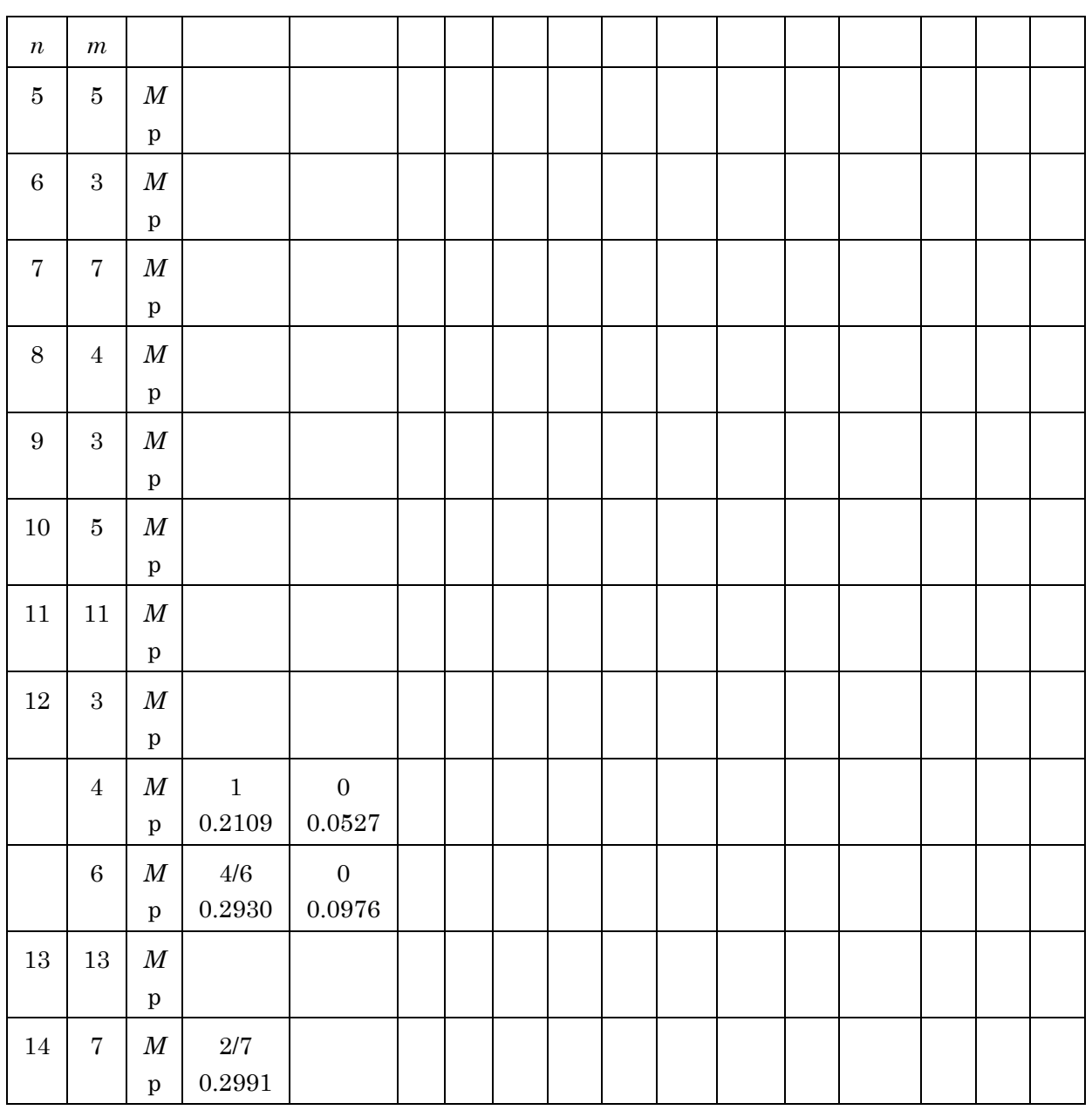


Table 7 (Continued) (Left half of the table)

\begin{tabular}{|c|c|c|c|c|c|c|c|c|c|c|c|c|}
\hline 15 & 5 & $\begin{array}{c}M \\
\mathrm{p}\end{array}$ & $\begin{array}{c}15 \\
0.0002\end{array}$ & $\begin{array}{c}59 / 5 \\
0.0039\end{array}$ & $\begin{array}{c}51 / 5 \\
0.005\end{array}$ & $\begin{array}{c}43 / 5 \\
0.0185\end{array}$ & $\begin{array}{c}7 \\
0.0736\end{array}$ & $\begin{array}{c}27 / 5 \\
0.1039\end{array}$ & $\begin{array}{c}19 / 5 \\
0.1832\end{array}$ & $\begin{array}{c}11 / 5 \\
0.3673\end{array}$ & $\begin{array}{c}3 / 5 \\
0.2444\end{array}$ & \\
\hline 16 & 4 & $\begin{array}{c}M \\
\mathrm{p}\end{array}$ & $\begin{array}{c}16 \\
0.0002\end{array}$ & $\begin{array}{c}13 \\
0.0039\end{array}$ & $\begin{array}{c}12 \\
0.0029\end{array}$ & $\begin{array}{c}10 \\
0.0234\end{array}$ & $\begin{array}{c}9 \\
0.0352\end{array}$ & $\begin{array}{c}8 \\
0.0132\end{array}$ & $\begin{array}{c}7 \\
0.0625\end{array}$ & $\begin{array}{c}6 \\
0.1406\end{array}$ & $\begin{array}{c}5 \\
0.1055\end{array}$ & $\begin{array}{c}4 \\
0.0889\end{array}$ \\
\hline & 8 & $\begin{array}{c}M \\
\mathrm{p}\end{array}$ & 16 & $\begin{array}{l}100 / 8 \\
0.001\end{array}$ & $\begin{array}{c}10 \\
0.0034\end{array}$ & $\begin{array}{c}9 \\
0.0039\end{array}$ & $\begin{array}{c}68 / 8 \\
0.0068\end{array}$ & $\begin{array}{c}8 \\
0.0043\end{array}$ & $\begin{array}{c}52 / 8 \\
0.0273\end{array}$ & $\begin{array}{c}5 \\
0.0547\end{array}$ & $\begin{array}{c}36 / 8 \\
0.0342\end{array}$ & $\begin{array}{c}4 \\
0.0479\end{array}$ \\
\hline 17 & 17 & $\begin{array}{c}M \\
\mathrm{p}\end{array}$ & 17 & $\begin{array}{l}225 / 17 \\
0.0003\end{array}$ & $\begin{array}{l}169 / 17 \\
0.0021\end{array}$ & $\begin{array}{l}121 / 17 \\
0.0104\end{array}$ & $\begin{array}{c}81 / 17 \\
0.0363\end{array}$ & $\begin{array}{c}49 / 17 \\
0.0944\end{array}$ & $\begin{array}{c}25 / 17 \\
0.1888\end{array}$ & $\begin{array}{c}9 / 17 \\
0.2968\end{array}$ & $\begin{array}{c}1 / 17 \\
0.3709\end{array}$ & \\
\hline 18 & 6 & $\begin{array}{c}M \\
\mathrm{p}\end{array}$ & 18 & $\begin{array}{c}88 / 6 \\
0.0005\end{array}$ & $\begin{array}{c}76 / 6 \\
0.0014\end{array}$ & $\begin{array}{c}12 \\
0.0009\end{array}$ & $\begin{array}{c}68 / 6 \\
0.0033\end{array}$ & $\begin{array}{c}56 / 6 \\
0.0165\end{array}$ & $\begin{array}{c}52 / 6 \\
0.011\end{array}$ & $\begin{array}{c}8 \\
0.0066\end{array}$ & $\begin{array}{c}44 / 6 \\
0.0206\end{array}$ & $\begin{array}{c}40 / 6 \\
0.0275\end{array}$ \\
\hline & 9 & $\begin{array}{l}M \\
\mathrm{p}\end{array}$ & 18 & $\begin{array}{c}130 / 9 \\
0.0003\end{array}$ & $\begin{array}{c}106 / 9 \\
0.0011\end{array}$ & $\begin{array}{c}98 / 9 \\
0.0012\end{array}$ & $\begin{array}{c}10 \\
0.0026\end{array}$ & $\begin{array}{c}82 / 9 \\
0.0038\end{array}$ & $\begin{array}{c}74 / 9 \\
0.0099\end{array}$ & $\begin{array}{c}58 / 9 \\
0.0231\end{array}$ & $\begin{array}{c}50 / 9 \\
0.0544\end{array}$ & $\begin{array}{c}34 / 9 \\
0.0923\end{array}$ \\
\hline 19 & 19 & $\begin{array}{c}M \\
\mathrm{p}\end{array}$ & 19 & 289/19 & $\begin{array}{l}225 / 19 \\
0.0007\end{array}$ & $\begin{array}{l}169 / 19 \\
0.0037\end{array}$ & $\begin{array}{l}121 / 19 \\
0.0148\end{array}$ & $\begin{array}{c}81 / 19 \\
0.0444\end{array}$ & $\begin{array}{c}49 / 19 \\
0.1035\end{array}$ & $\begin{array}{c}25 / 19 \\
0.1922\end{array}$ & $\begin{array}{c}9 / 19 \\
0.2883\end{array}$ & $\begin{array}{c}1 / 19 \\
0.3524\end{array}$ \\
\hline 20 & 5 & $\begin{array}{c}M \\
\mathrm{p}\end{array}$ & 20 & $\begin{array}{c}84 / 5 \\
0.0003\end{array}$ & $\begin{array}{c}76 / 5 \\
0.0006\end{array}$ & $\begin{array}{c}68 / 5 \\
0.0023\end{array}$ & $\begin{array}{c}12 \\
0.0092\end{array}$ & $\begin{array}{c}52 / 5 \\
0.0168 \\
\end{array}$ & $\begin{array}{c}44 / 5 \\
0.0458\end{array}$ & $\begin{array}{c}36 / 5 \\
0.1011\end{array}$ & $\begin{array}{c}28 / 4 \\
0.1373\end{array}$ & $\begin{array}{c}4 \\
0.2289 \\
\end{array}$ \\
\hline & 10 & $\begin{array}{c}M \\
\mathrm{p}\end{array}$ & 20 & $16 . / 4$ & $\begin{array}{c}13.6 \\
0.0003\end{array}$ & $\begin{array}{c}12.8 \\
0.0004\end{array}$ & $\begin{array}{c}11.6 \\
0.0009\end{array}$ & $\begin{array}{c}10.4 \\
0.0018\end{array}$ & $\begin{array}{c}10 \\
0.0044\end{array}$ & $\begin{array}{c}8 \\
0.0095\end{array}$ & $\begin{array}{c}7.2 \\
0.0069\end{array}$ & $\begin{array}{c}6.8 \\
0.0163\end{array}$ \\
\hline 21 & 7 & $\begin{array}{c}M \\
\mathrm{p}\end{array}$ & 21 & $123 / 7$ & $\begin{array}{c}107 / 7 \\
0.0002\end{array}$ & $\begin{array}{c}99 / 7 \\
0.001\end{array}$ & $\begin{array}{c}83 / 7 \\
0.0034\end{array}$ & $\begin{array}{c}75 / 7 \\
0.0069\end{array}$ & $\begin{array}{c}67 / 7 \\
0.005\end{array}$ & $\begin{array}{c}59 / 7 \\
0.0286\end{array}$ & $\begin{array}{c}51 / 7 \\
0.0336\end{array}$ & $\begin{array}{c}437 / \\
0.0354\end{array}$ \\
\hline 22 & 11 & $\begin{array}{c}M \\
\mathrm{p}\end{array}$ & 22 & $202 / 11$ & $\begin{array}{l}170 / 11 \\
0.0001\end{array}$ & $\begin{array}{l}162 / 11 \\
0.0001\end{array}$ & $\begin{array}{l}146 / 11 \\
0.0003\end{array}$ & $\begin{array}{l}130 / 11 \\
0.0018\end{array}$ & $\begin{array}{l}122 / 11 \\
0.0009\end{array}$ & $\begin{array}{l}106 / 11 \\
0.0035\end{array}$ & $\begin{array}{c}98 / 11 \\
0.0029\end{array}$ & $\begin{array}{c}90 / 11 \\
0.0069\end{array}$ \\
\hline 23 & 23 & $\begin{array}{c}M \\
\mathrm{p}\end{array}$ & 23 & $441 / 23$ & $361 / 23$ & $\begin{array}{l}289 / 23 \\
0.0004\end{array}$ & $\begin{array}{l}225 / 23 \\
0.0021\end{array}$ & $\begin{array}{c}169 / 23 \\
0.008\end{array}$ & $\begin{array}{l}121 / 23 \\
0.0241\end{array}$ & $\begin{array}{c}81 / 23 \\
0.0584\end{array}$ & $\begin{array}{c}49 / 23 \\
0.1169\end{array}$ & $\begin{array}{c}25 / 23 \\
0.1949\end{array}$ \\
\hline
\end{tabular}


(Right half of the table)

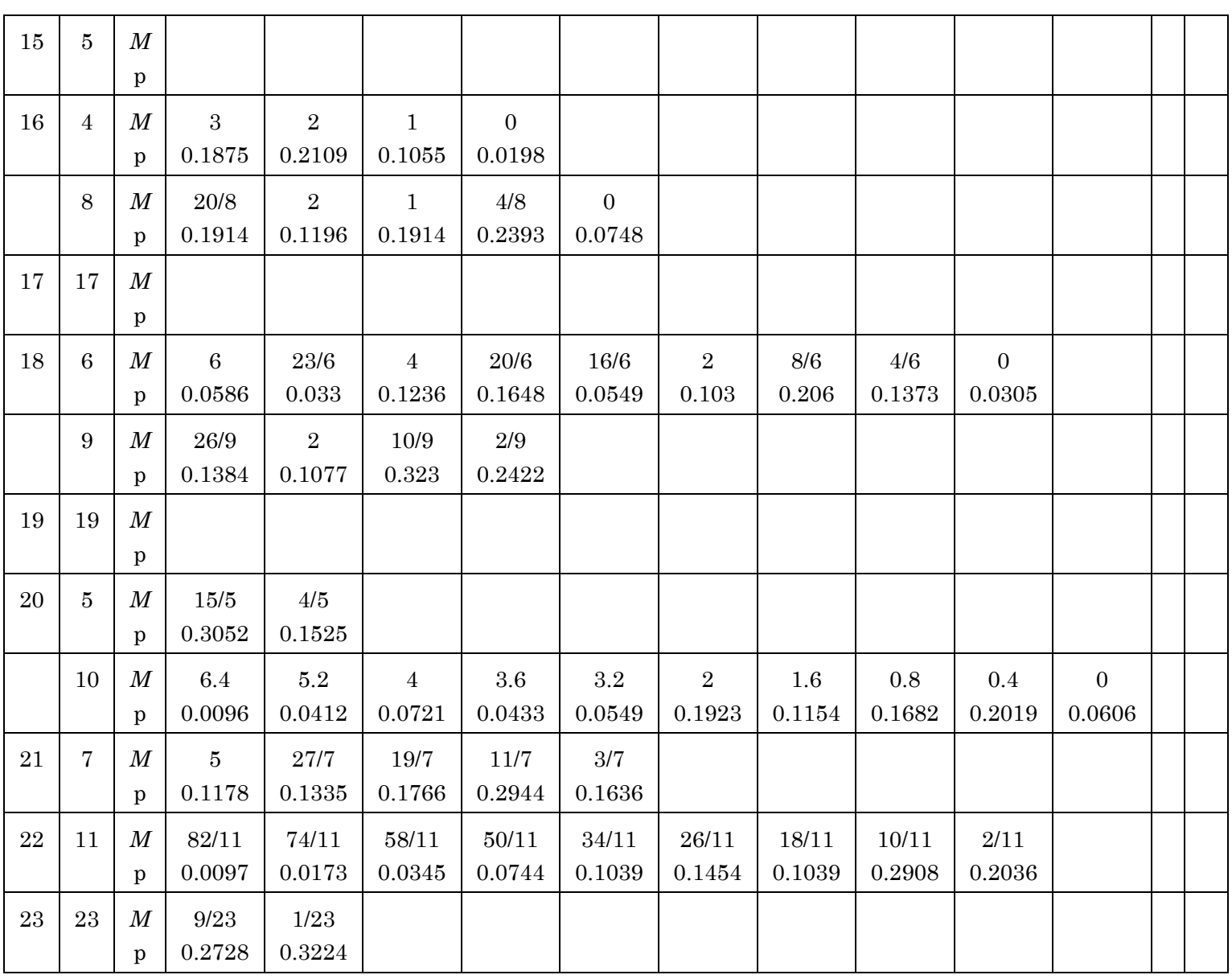


Table 7 (Continued) (Left half of the table)

\begin{tabular}{|c|c|c|c|c|c|c|c|c|c|c|c|c|}
\hline 24 & 6 & $\begin{array}{c}M \\
\mathrm{p}\end{array}$ & 24 & $124 / 6$ & $112 / 6$ & 18 & $\begin{array}{c}104 / 6 \\
0.0002\end{array}$ & $\begin{array}{c}92 / 6 \\
0.001 \\
\end{array}$ & $\begin{array}{c}88 / 6 \\
0.0007 \\
\end{array}$ & $\begin{array}{c}14 \\
0.0008 \\
\end{array}$ & $\begin{array}{c}80 / 6 \\
0.0013 \\
\end{array}$ & $\begin{array}{c}76 / 6 \\
0.0018 \\
\end{array}$ \\
\hline & & $\begin{array}{c}M \\
\mathrm{p}\end{array}$ & $\begin{array}{c}4 \\
0.1545 \\
\end{array}$ & $\begin{array}{c}20 / 6 \\
0.103\end{array}$ & $\begin{array}{c}16 / 6 \\
0.0712\end{array}$ & $\begin{array}{c}2 \\
0.1287 \\
\end{array}$ & $\begin{array}{c}8 / 6 \\
0.1287\end{array}$ & $\begin{array}{c}4 / 6 \\
0.0572 \\
\end{array}$ & $\begin{array}{c}0 \\
0.0095\end{array}$ & & & \\
\hline & 8 & $\begin{array}{c}M \\
\mathrm{p}\end{array}$ & 24 & $164 / 8$ & 18 & 17 & $132 / 8$ & 16 & $\begin{array}{c}116 / 8 \\
0.0006 \\
\end{array}$ & $\begin{array}{c}108 / 8 \\
0.0003 \\
\end{array}$ & $\begin{array}{c}104 / 8 \\
0.0013 \\
\end{array}$ & $\begin{array}{c}100 / 8 \\
0.0009 \\
\end{array}$ \\
\hline & & $\begin{array}{c}M \\
\mathrm{p}\end{array}$ & $\begin{array}{c}5 \\
0.0449 \\
\end{array}$ & $\begin{array}{c}36 / 8 \\
0.0768\end{array}$ & $\begin{array}{c}4 \\
0.0395\end{array}$ & $\begin{array}{c}3 \\
0.1256\end{array}$ & $\begin{array}{c}20 / 8 \\
0.157\end{array}$ & $\begin{array}{c}2 \\
0.0491\end{array}$ & $\begin{array}{c}12 / 8 \\
0.0834\end{array}$ & $\begin{array}{c}1 \\
0.157\end{array}$ & $\begin{array}{c}4 / 8 \\
0.0981\end{array}$ & $\begin{array}{c}0 \\
0.0204\end{array}$ \\
\hline 25 & 5 & $\begin{array}{c}M \\
\mathrm{p}\end{array}$ & 25 & $109 / 5$ & $101 / 5$ & $\begin{array}{c}93 / 5 \\
0.0002\end{array}$ & $\begin{array}{c}17 \\
0.001\end{array}$ & $\begin{array}{c}77 / 5 \\
0.0021\end{array}$ & $\begin{array}{c}69 / 5 \\
0.0072\end{array}$ & $\begin{array}{c}61 / 5 \\
0.0170\end{array}$ & $\begin{array}{c}53 / 5 \\
0.0334\end{array}$ & $\begin{array}{c}9 \\
0.0745 \\
\end{array}$ \\
\hline \multirow[t]{3}{*}{26} & 13 & $\begin{array}{c}M \\
\mathrm{p} \\
\end{array}$ & 26 & $290 / 13$ & $250 / 13$ & $242 / 13$ & $218 / 13$ & $\begin{array}{l}202 / 13 \\
0.0001 \\
\end{array}$ & $\begin{array}{l}194 / 13 \\
0.0001 \\
\end{array}$ & $\begin{array}{l}178 / 13 \\
0.0002 \\
\end{array}$ & $\begin{array}{l}170 / 13 \\
0.0006\end{array}$ & $\begin{array}{l}162 / 13 \\
0.0004 \\
\end{array}$ \\
\hline & & $\begin{array}{c}M \\
\mathrm{p}\end{array}$ & $\begin{array}{c}18 / 13 \\
0.0987\end{array}$ & $\begin{array}{c}10 / 13 \\
0.2633 \\
\end{array}$ & $\begin{array}{c}2 / 13 \\
0.1744 \\
\end{array}$ & & & & & & & \\
\hline & 9 & $\begin{array}{c}M \\
\mathrm{p} \\
\end{array}$ & 27 & $211 / 9$ & $187 / 9$ & $179 / 9$ & 19 & $163 / 9$ & $\begin{array}{c}155 / 9 \\
0.0001 \\
\end{array}$ & $147 / 9$ & $\begin{array}{c}139 / 9 \\
0.0003 \\
\end{array}$ & $\begin{array}{c}131 / 9 \\
0.0006 \\
\end{array}$ \\
\hline 27 & & $\begin{array}{c}M \\
\mathrm{p}\end{array}$ & $\begin{array}{c}3 \\
0.1375 \\
\end{array}$ & $\begin{array}{c}19 / 9 \\
0.159 \\
\end{array}$ & $\begin{array}{c}11 / 9 \\
0.2385\end{array}$ & $\begin{array}{c}3 / 9 \\
0.1192 \\
\end{array}$ & & & & & & \\
\hline 28 & 7 & $\begin{array}{c}M \\
\mathrm{p}\end{array}$ & 28 & $172 / 7$ & $156 / 7$ & $148 / 7$ & $\begin{array}{c}132 / 7 \\
0.0001 \\
\end{array}$ & $\begin{array}{c}124 / 7 \\
0.0003 \\
\end{array}$ & $\begin{array}{c}116 / 7 \\
0.0002\end{array}$ & $\begin{array}{c}108 / 7 \\
0.0013\end{array}$ & $\begin{array}{c}100 / 7 \\
0.0018 \\
\end{array}$ & $\begin{array}{c}92 / 7 \\
0.0022 \\
\end{array}$ \\
\hline 29 & 29 & $\begin{array}{c}M \\
\mathrm{p}\end{array}$ & 29 & $729 / 29$ & $625 / 29$ & $529 / 29$ & $441 / 29$ & $\begin{array}{l}361 / 29 \\
0.0004 \\
\end{array}$ & $\begin{array}{l}289 / 29 \\
0.0018 \\
\end{array}$ & $\begin{array}{l}225 / 29 \\
0.0058 \\
\end{array}$ & $\begin{array}{c}169 / 29 \\
0.016 \\
\end{array}$ & $\begin{array}{l}121 / 29 \\
0.0374 \\
\end{array}$ \\
\hline \multirow[t]{5}{*}{30} & 10 & $\begin{array}{c}M \\
\mathrm{p}\end{array}$ & 30 & 26.4 & 23.6 & 22.8 & 21.6 & 20.4 & 20 & 19.2 & $\begin{array}{c}18 \\
0.0001 \\
\end{array}$ & 17.2 \\
\hline & & $\begin{array}{c}M \\
\mathrm{p}\end{array}$ & $\begin{array}{c}10 \\
0.0029\end{array}$ & $\begin{array}{c}9.6 \\
0.0032\end{array}$ & $\begin{array}{c}8.8 \\
0.0054\end{array}$ & $\begin{array}{c}8.4 \\
0.0113\end{array}$ & $\begin{array}{c}8 \\
0.0068\end{array}$ & $\begin{array}{c}7.6 \\
0.0095\end{array}$ & $\begin{array}{c}7.2 \\
0.0156\end{array}$ & $\begin{array}{c}6.8 \\
0.0263\end{array}$ & $\begin{array}{c}6.4 \\
0.0035\end{array}$ & $\begin{array}{c}5.6 \\
0.0507\end{array}$ \\
\hline & & $\begin{array}{c}M \\
\mathrm{p} \\
\end{array}$ & $\begin{array}{c}0 \\
0.0149 \\
\end{array}$ & & & & & & & & & \\
\hline & 15 & $\begin{array}{c}M \\
\mathrm{p}\end{array}$ & 30 & $394 / 15$ & $346 / 15$ & $338 / 15$ & $306 / 15$ & $290 / 15$ & $274 / 15$ & $250 / 15$ & $242 / 15$ & $234 / 15$ \\
\hline & & $\begin{array}{c}M \\
\mathrm{p}\end{array}$ & $\begin{array}{c}6 \\
0.017\end{array}$ & $\begin{array}{c}82 / 15 \\
0.0218\end{array}$ & $\begin{array}{c}74 / 15 \\
0.0305\end{array}$ & $\begin{array}{c}58 / 15 \\
0.0509\end{array}$ & $\begin{array}{l}50 / 15 \\
0.099\end{array}$ & $\begin{array}{l}34 / 15 \\
0.112\end{array}$ & $\begin{array}{l}26 / 15 \\
0.144\end{array}$ & $\begin{array}{c}18 / 15 \\
0.0933\end{array}$ & $\begin{array}{c}10 / 15 \\
0.24\end{array}$ & $\begin{array}{c}2 / 15 \\
0.1543\end{array}$ \\
\hline
\end{tabular}


(Right half of the table)

\begin{tabular}{|c|c|c|c|c|c|c|c|c|c|c|c|c|c|c|}
\hline 24 & 6 & $\begin{array}{c}M \\
\mathrm{p}\end{array}$ & $\begin{array}{c}12 \\
0.0068\end{array}$ & $\begin{array}{c}68 / 6 \\
0.0042\end{array}$ & $\begin{array}{c}64 / 6 \\
0.0013\end{array}$ & $\begin{array}{c}10 \\
0.0154\end{array}$ & $\begin{array}{c}56 / 6 \\
0.0206\end{array}$ & $\begin{array}{c}52 / 6 \\
0.0193\end{array}$ & $\begin{array}{c}8 \\
0.0212\end{array}$ & $\begin{array}{c}44 / 6 \\
0.0257\end{array}$ & $\begin{array}{c}40 / 6 \\
0.0635\end{array}$ & $\begin{array}{c}6 \\
0.0656\end{array}$ & $\begin{array}{c}32 / 6 \\
0.0206\end{array}$ & $\begin{array}{c}28 / 6 \\
0.0772\end{array}$ \\
\hline & & $\begin{array}{c}M \\
\mathrm{p} \\
\end{array}$ & & & & & & & & & & & & \\
\hline & 8 & $\begin{array}{c}M \\
\mathrm{p}\end{array}$ & $\begin{array}{c}12 \\
0.0011\end{array}$ & $\begin{array}{c}11 \\
0.0026\end{array}$ & $\begin{array}{c}84 / 8 \\
0.0046\end{array}$ & $\begin{array}{c}10 \\
0.0028\end{array}$ & $\begin{array}{c}76 / 8 \\
0.0052\end{array}$ & $\begin{array}{c}9 \\
0.0077\end{array}$ & $\begin{array}{c}68 / 8 \\
0.0146\end{array}$ & $\begin{array}{c}8 \\
0.0018\end{array}$ & $\begin{array}{c}7 \\
0.0359\end{array}$ & $\begin{array}{c}52 / 8 \\
0.0224\end{array}$ & $\begin{array}{c}6 \\
0.0105\end{array}$ & $\begin{array}{c}44 / 8 \\
0.0359\end{array}$ \\
\hline & & $\begin{array}{c}M \\
\mathrm{p}\end{array}$ & & & & & & & & & & & & \\
\hline 25 & 5 & $\begin{array}{c}M \\
\mathrm{p}\end{array}$ & $\begin{array}{c}37 / 5 \\
0.1252\end{array}$ & $\begin{array}{c}29 / 5 \\
0.1669\end{array}$ & $\begin{array}{c}21 / 5 \\
0.2385\end{array}$ & $\begin{array}{c}13 / 5 \\
0.2386\end{array}$ & $\begin{array}{c}1 \\
0.0954\end{array}$ & & & & & & & \\
\hline 26 & 13 & $\begin{array}{c}M \\
\mathrm{p}\end{array}$ & $\begin{array}{l}146 / 13 \\
0.0011\end{array}$ & $\begin{array}{c}10 \\
0.0047\end{array}$ & $\begin{array}{l}122 / 13 \\
0.0027\end{array}$ & $\begin{array}{l}106 / 13 \\
0.0066\end{array}$ & $\begin{array}{l}98 / 13 \\
0.049\end{array}$ & $\begin{array}{c}90 / 13 \\
0.0120\end{array}$ & $\begin{array}{c}82 / 13 \\
0.0160\end{array}$ & $\begin{array}{c}74 / 13 \\
0.0244\end{array}$ & $\begin{array}{c}58 / 13 \\
0.0439\end{array}$ & $\begin{array}{c}50 / 13 \\
0.0890\end{array}$ & $\begin{array}{c}34 / 13 \\
0.1097\end{array}$ & $\begin{array}{c}2 \\
0.1463\end{array}$ \\
\hline & & $\begin{array}{c}M \\
\mathrm{p} \\
\end{array}$ & & & & & & & & & & & & \\
\hline & 9 & $\begin{array}{c}M \\
\mathrm{p}\end{array}$ & $\begin{array}{c}123 / 9 \\
0.0005\end{array}$ & $\begin{array}{c}115 / 9 \\
0.0011\end{array}$ & $\begin{array}{c}107 / 9 \\
0.0028\end{array}$ & $\begin{array}{c}11 \\
0.0052\end{array}$ & $\begin{array}{c}91 / 9 \\
0.0038\end{array}$ & $\begin{array}{c}83 / 9 \\
0.0126\end{array}$ & $\begin{array}{c}75 / 9 \\
0.0174\end{array}$ & $\begin{array}{c}67 / 9 \\
0.0114\end{array}$ & $\begin{array}{c}59 / 9 \\
0.0535\end{array}$ & $\begin{array}{c}51 / 9 \\
0.0547\end{array}$ & $\begin{array}{c}43 / 9 \\
0.0454\end{array}$ & $\begin{array}{c}35 / 9 \\
0.1363\end{array}$ \\
\hline 27 & & $\begin{array}{c}M \\
\mathrm{p}\end{array}$ & & & & & & & & & & & & \\
\hline 28 & 7 & $\begin{array}{c}M \\
\mathrm{p} \\
\end{array}$ & $\begin{array}{c}12 \\
0.0091 \\
\end{array}$ & $\begin{array}{c}76 / 7 \\
0.0112 \\
\end{array}$ & $\begin{array}{c}68 / 7 \\
0.0193 \\
\end{array}$ & $\begin{array}{c}60 / 7 \\
0.0441 \\
\end{array}$ & $\begin{array}{c}52 / 7 \\
0.0471 \\
\end{array}$ & $\begin{array}{c}44 / 7 \\
0.0772 \\
\end{array}$ & $\begin{array}{c}36 / 7 \\
0.1402 \\
\end{array}$ & $\begin{array}{c}4 \\
0.1487 \\
\end{array}$ & $\begin{array}{c}20 / 7 \\
0.1931 \\
\end{array}$ & $\begin{array}{c}12 / 7 \\
0.2147 \\
\end{array}$ & $\begin{array}{c}4 / 7 \\
0.0894 \\
\end{array}$ & \\
\hline 29 & 29 & $\begin{array}{c}M \\
\mathrm{p}\end{array}$ & $\begin{array}{c}81 / 29 \\
0.0747\end{array}$ & $\begin{array}{c}49 / 29 \\
0.1289\end{array}$ & $\begin{array}{c}25 / 19 \\
0.1933\end{array}$ & $\begin{array}{c}9 / 29 \\
0.2528 \\
\end{array}$ & $\begin{array}{c}1 / 29 \\
0.2889\end{array}$ & & & & & & & \\
\hline 30 & 10 & $\begin{array}{c}M \\
\mathrm{p}\end{array}$ & $\begin{array}{c}16.8 \\
0.0001\end{array}$ & $\begin{array}{c}16.4 \\
0.0002\end{array}$ & $\begin{array}{c}15.2 \\
0.0002\end{array}$ & $\begin{array}{c}14.4 \\
0.0003\end{array}$ & $\begin{array}{c}14 \\
0.0004\end{array}$ & $\begin{array}{c}13.6 \\
0.0007\end{array}$ & $\begin{array}{c}13.2 \\
0.0008\end{array}$ & $\begin{array}{c}12.8 \\
0.0003\end{array}$ & $\begin{array}{c}12 \\
0.0011\end{array}$ & $\begin{array}{c}11.6 \\
0.0031\end{array}$ & $\begin{array}{c}10.8 \\
0.0017\end{array}$ & $\begin{array}{c}10.4 \\
0.0054\end{array}$ \\
\hline & & $\begin{array}{c}M \\
\mathrm{p} \\
\end{array}$ & $\begin{array}{c}5.2 \\
0.0304 \\
\end{array}$ & $\begin{array}{c}4.8 \\
0.0129 \\
\end{array}$ & $\begin{array}{c}4.4 \\
0.0444 \\
\end{array}$ & $\begin{array}{c}4 \\
0.0532 \\
\end{array}$ & $\begin{array}{c}3.6 \\
0.0836 \\
\end{array}$ & $\begin{array}{c}3.2 \\
0.0406 \\
\end{array}$ & $\begin{array}{c}2.4 \\
0.1183 \\
\end{array}$ & $\begin{array}{c}2 \\
01419 \\
\end{array}$ & $\begin{array}{c}1.6 \\
0.0426 \\
\end{array}$ & $\begin{array}{c}1.2 \\
0.069 \\
\end{array}$ & $\begin{array}{c}0.8 \\
0.1242 \\
\end{array}$ & $\begin{array}{c}0.4 \\
0.0745 \\
\end{array}$ \\
\hline & & $\begin{array}{c}M \\
\mathrm{p}\end{array}$ & & & & & & & & & & & & \\
\hline & 15 & $\begin{array}{c}M \\
\mathrm{p}\end{array}$ & $226 / 15$ & $\begin{array}{l}218 / 15 \\
0.0002\end{array}$ & $\begin{array}{l}202 / 15 \\
0.0004\end{array}$ & $\begin{array}{l}194 / 15 \\
0.0003\end{array}$ & $\begin{array}{l}178 / 15 \\
0.0006\end{array}$ & $\begin{array}{l}170 / 15 \\
0.0018\end{array}$ & $\begin{array}{l}162 / 15 \\
0.0008\end{array}$ & $\begin{array}{l}146 / 15 \\
0.0023\end{array}$ & $\begin{array}{l}130 / 15 \\
0.0085\end{array}$ & $\begin{array}{c}122 / 15 \\
0.005\end{array}$ & $\begin{array}{l}106 / 15 \\
0.0102\end{array}$ & $\begin{array}{c}98 / 15 \\
0.0069\end{array}$ \\
\hline & & $\begin{array}{c}M \\
\mathrm{p}\end{array}$ & & & & & & & & & & & & \\
\hline
\end{tabular}

